\title{
Policy Formation and Debate Concerning the Government Regulation of Ayurveda in Great Britain in the 21st Century
}

\author{
Dominik Wujastyk \\ [Draft of 2 Oct 2004]
}

\begin{abstract}
Since 2000, the British House of Lords and the Government have been working towards a regulatory scheme for Complementary and Alternative medicine in Britain, a scheme that will include ayurveda. The present paper discusses these regulatory moves by the Government, and suggests that shortcomings in the range and type of evidence taken into account by the various Government agencies will leave a legacy of difficulties for CAM practitioners and their patients.
\end{abstract}

\section{The House of Lords Select Committees}

The House of Lords, the upper house of the British Government, has the power to appoint 'Select Committees' which return reports on particular topics on which the Government requires specialized information and judgements. ${ }^{1}$ Past committees have reported on such topics as the use of animals in scientific experimentation, the monetary policy of the Bank of England, and religious offences in England and Wales. ${ }^{2}$ The House of Lords Select Committee on Science and Technology was established in 1979 with a broad remit 'to consider science and technology,' and it works in the following fields: ${ }^{3}$

- Public policy areas which are, or ought to be, informed by scientific

\footnotetext{
${ }^{1}$ See 'General Information about House of Lords' Select Committees' at http://www. parliament.the-stationery-office.co.uk/pa/ld199697/ldselect/ldscgen.htm.

${ }^{2}$ For a list of topics, see http://www.parliament.the-stationery-office.co.uk/ $\mathrm{pa} / \mathrm{ld} / \mathrm{ldselect.htm}$

${ }^{3}$ See http://www.parliament.the-stationery-office.co.uk/pa/ld200102/ ldinfo/infonote.htm.
} 
research: e.g. health effects of air travel, complementary and alternative medicine, legal status of cannabis.

- Technological challenges and opportunities - existing and future which government faces or ought to face: e.g. resistance to antibiotics, management of nuclear waste, human genetic databases, innovations in microprocessing, and the implications of digital imaging for the law of evidence.

- Public policy towards science itself, e.g. as it affects Research Councils, schools and universities, public sector research establishments and industrial research and development.

Its work is principally carried out through Inquiries. Each Inquiry is conducted by a subcommittee of specialists and prominent establishment figures, and leads to a report, published together with the evidence on which it is based, setting out the subcommittee's findings and making recommendations to the Government and others. Some of the reports appear in print, and an increasing number also appear on the internet.

The Government does not always accept the main recommendations of a subcommittee's reports. This happened, for example, with the report 'Cannabis, The Scientific and Medical Evidence.' This report recommended that cannabis should be legalised for medical use, and although this was rejected by the Government at the time, the Lords felt, rightly, that report had raised the profile of a difficult issue and given encouragement to research, which is now well under way.

\section{The House of Lords Select Sub-Committee on CAM: 1999-2000}

In the 1999-2000 session, the The House of Lords Select Committee on Science and Technology produced six reports, the last of which was entitled 'Complementary and Alternative Medicine' (henceforth the 'Report') $4_{4}^{4}$ In this report, a Lords sub-committee set themselves the immense task of characterising all aspects of Complementary and Alternative Medicine (henceforth 'CAM'). In their report they attempted to survey the use of CAM in Britain and and the USA, they examined the topics of patient satisfaction, the role of the therapist, the placebo effect, the evidence for efficacy and safety, statutory- and self-regulation, professional training and education of practitioners, research and development in CAM (including methodology and funding), public information dissemination, and CAM health-care

${ }^{4}$ House of Lords Select Committee on Science and Technology 2000. 
delivery. The report included appendices on randomised controlled testing, and accounts of visits to particular CAM centres. The Committee was chaired by Lord Walton of Detchant, and consisted of a number of peers. ${ }^{5}$ The documentation accompanying the report states that only seven of the eleven members of the sub-committee had special 'declared interests' related to CAM issues: two were on the Parliamentary Group on Alternative and Complementary Medicine, the Natural Medicines Society and the National Federation of Spiritual Healers; the other five were academics or practitioners of modern establishment medicine (henceforth MEM) men with only tangential involvement with CAM. However, the sub-committee took special advice from Professor Stephen Holgate, Clinical Professor of Immunopharmacology, University of Southampton, and Mr Simon Mills, Director of the Centre for Complementary Health Studies, University of Exeter. It appears that there was no representation on the sub-committee from medical anthropology, medical sociology, or medical history, fields which would appear prima-facie to be essential to an understanding of the issues the committee was grappling with.

The central achievement of the report was to divide CAM therapies into three large groups and to support practices falling into Group 1, and deprecate those in Group 3 (See Table 1). Therapies in Group 2, that 'mainly make claims in the area of relaxation and stress management', were approved when used as adjuncts to conventional medicine. As may have been predicted, this finding caused a great deal of consternation amongst CAM practitioners of almost all traditions. In the aftermath of the publication, for example, the Indian Government went as far as to send a delegation of senior ayurvedic practitioners to the House of Lords to meet Lord Walton and discuss the Group 3 classification given to their practice. ${ }^{6}$ Many commentators noted that the presence of 'Acupuncture' in Group 1 was at odds with the appearance of essentially the same practice as 'Traditional Chinese Medicine' (TCM) in Group 3.7 This distinction appeared to reflect little more than the greater lobbying powers of the Society of Medical Acupuncturists (qualified MDs) over those of the community of TCM prac-

${ }^{5}$ Earl Baldwin of Bewdley, Lord Colwyn, Lord Haskel, Lord Howie of Troon, Lord Perry of Walton, Lord Quirk, Lord Rea, Lord Smith of Clifton, Lord Soulsby of Swaffham Prior, and Lord Tombs. See http://www.parliament.the-stationery-office.co. uk/pa/ld199900/ldselect/ldsctech/123/12329.htm.

${ }^{6}$ Personal communication from Dr Shailaja Chandra, then Secretary of the Indian Ministry of Health \& Family Welfare, Department of Indian Systems of Medicine \& Homoeopathy. The delegation included Dr Narendra Bhatt, currently a member of the IASTAM Council.

${ }^{7}$ Personal communications from Dr Vivienne Lo and other colleagues. 
Group 1 The first group embraces what may be called the principal disciplines, two of which, osteopathy and chiropractic, are already regulated in their professional activity and education by Acts of Parliament. The others are acupuncture, herbal medicine and homeopathy. Each of these therapies claims to have an individual diagnostic approach and are seen as the 'Big 5' by most of the CAM world.

Group 2 The second group contains therapies which are most often used to complement conventional medicine and do not purport to embrace diagnostic skills. It includes aromatherapy; the Alexander Technique; body work therapies, including massage; counselling, stress therapy; hypnotherapy; reflexology and probably shiatsu, meditation and healing.

Group 3 The third group embraces those other disciplines which purport to offer diagnostic information as well as treatment and which, in general, favour a philosophical approach and are indifferent to the scientific principles of conventional medicine, and through which various and disparate frameworks of disease causation and its management are proposed. These therapies can be split into two subgroups:

Group 3a includes long-established and traditional systems of healthcare such as Ayurvedic medicine and Traditional Chinese medicine.

Group $3 \mathbf{b}$ covers other alternative disciplines which lack any credible evidence base such as crystal therapy, iridology, radionics, dowsing and kinesiology.

Table 1: The CAM groups identified by the House of Lords Select Committee. Cited from the Committee's Report, 'Summary of Recommendations'. 


\footnotetext{
${ }^{8}$ These were said to have been published in the printed form of the final report, but do not appear on the report's website.

${ }^{9}$ [See now the Indian Government website, http://indianmedicine.nic.in/.]

${ }^{10}$ IASTAM; http://www.iastam.org. [The present Secretary-General is Dr Vivienne Lo.]
}

\section{The Submission of the Secretary-General of IASTAM: 1999}

In the year before publication, 1999, the House of Lords sub-committee invited interested parties to submit statements for their consideration. 8 I submitted the following statement, which has been lightly edited for the present publication. Footnotes added at the time of present writing are enclosed in square brackets.

\section{Scope}

My remarks are directed to ayurveda, the traditional medical system of India. In India the government supports this medical system financially and administratively as part of the national policy of supporting plural medicine (Unāni, Yoga, and Siddha medicine are also supported)..$^{9}$ Outside India, ayurveda has in recent years been gaining a following in Europe and America as part of the CAM scene.

\section{Credentials}

My published works on the history of Indian medicine include the volume in the Penguin Classics series entitled The Roots of Äyurveda (Wujastyk 1998) which presents my own translations of ayurvedic medical texts from the original Sanskrit, together with a historical introduction to the subject. I have also published research and survey articles on ayurveda and Indian medical history in refereed journals and in such volumes as The Companion Encyclopedia of the History of Medicine (Wujastyk 1993), Oriental Medicine: an Illustrated Guide to the Asian Arts of Healing (Wujastyk 1995), and Religion, Health and Suffering (Wujastyk 1999). I teach an MA unit on the history of ayurveda at the School of Oriental and African Studies, where I am a Research Associate. I am not a medical practitioner (my doctorate is a DPhil.). I am currently Secretary-General of the International Association for the Study of Traditional Asian Medicine. ${ }^{10}$

\section{Terminology}

I should like to make a preliminary remark regarding the appropriateness or otherwise of the term 'Complementary and Alternative Medicine' (CAM) used to 
refer to the medical systems listed in the Committee's 'Call for Evidence' letter, and in the name of the Committee. The medical systems listed in that letter (Acupuncture - Yoga) are widely divergent in their presuppositions, their histories, their techniques, their stands vis-à-vis contemporary European establishment medicine, and so forth. Whatever name is chosen to refer to them collectively will inevitably betray certain presuppositions on our behalf. All such names are contested. The name CAM attempts to avoid certain types of controversy by including two ideas, complementarity and alternativeness, which each suggest something rather different about the nature of these therapies. This attempt is only partially successful, and there are several underlying assumptions in the name CAM which are undesirable from some points of view. This difficult issue has been discussed in a valuable paper by Matthew Ramsey published recently in the special issue of the journal Medical History dedicated to 'Alternative Medicine in Europe since 1800' 11 Ramsey gives serious arguments for the use of the terms 'medical outsiders', 'nonstandard medicine(s)' and 'counterhegemonic medicine' in various contexts. I would draw the Committee's attention to this brief but lucid discussion, which can serve to raise awareness of several critical issues which are implicit in the Committee's name and documentation.

\section{Evidence}

Controlled clinical trials are an inevitable component of any attempt to bring the practice of CAMs under the same funding, institutional, and managerial structures as contemporary biomedicine, whether in Europe or in India or other Asian countries. India, for example, has a long history of modern scientific research in evaluating traditional medical herbs through laboratory testing. There are numerous centres which undertake such work, amongst which the Central Drug Research Institute in Lucknow takes a leading role ${ }^{12}$

However, the Committee should be aware that in some circles this a controversial matter. For example, papers by Darshan Shankar, Director of the FRLHT (see below, p. 9, 914), and his colleagues, have argued passionately that the traditional knowledge systems which developed in India over many centuries and whose theories justify the application of particular herbs, are an integral component of a treatment situation. To take a herb, for instance, that has a history of traditional use in India, to remove it from its traditional epistemological setting and to appropriate it for international use through ethnopharmacological analysis and synthesis is to lose an essential component of the medical situation ${ }^{13}$

${ }^{11}$ Ramsey 1999

${ }^{12}$ Cf. http://www . cdriindia.org.

${ }^{13}$ See, e.g., Shankar and Manohar 1995, and Shankar 1995. [To which could be added Shiva 1988]. 
It is also important in this context to be sensitive to the patenting issues which have caused so much public outcry in India in recent years. The case of the American patent on a particular Neem tree oil compound is just the bestknown of several such cases in which medicinal plants with long histories of traditional use have been crudely appropriated by foreign companies for profit under exclusive terms which have profound economic and social repercussions in India.

\section{Public Information}

This is a critical issue for ayurveda. It is difficult for either doctors or patients to lay hands on reliable information on ayurveda. Two things are needed: first, sound guides to the small number of important and reliable information sources that do exist; second, the production of more informational works which are based on scholarly research.

The last decade has seen an explosion in the publication of popular works promoting ayurveda as a new therapy for the West, as well as for the westernized middle classes in India. All these books are written by authors who are primarily interested in promoting ayurvedic therapy in practice. But these authors may not have either an awareness of historical issues bearing on ayurveda, or any linguistic abilities in Sanskrit. They may have a strong vested interest in increasing their client base. The dominance of this kind of literature is not useful when trying to come to a balanced and properly-informed opinion about ayurvedic medicine. But it often seems to be the only literature easily available through normal channels.

Sanskrit remains vitally important in this respect because it is the language in which the bulk of ayurvedic literature is written. Only a relatively small amount of this literature is available in English translation, and most of this is produced for a reading public in India which is fluent in Hindi and therefore conversant with the many technical terms in Sanskrit which are not translated. More translated texts are available in Hindi and other regional languages of India. But as recently as 1920s, the great ayurvedic scholar Gananath Sen chose to write his works in Sanskrit on the grounds that it was the only lingua franca amongst ayurvedic practitioners in all parts of India. His books were still being reprinted, in Sanskrit, in the 1960s. Not only is Sanskrit important for access to many primary works; it is also important because the epistemological basis of ayurveda makes use of many concepts and categories which are embedded in Sanskrit culture. The philosopher wishing to work professionally on the opus of Plato or Aristotle must acquire Greek; a serious researcher into Chinese medicine would be expected to have some knowledge of the Chinese language. Similarly, serious scholars and interpreters of ayurveda must have a good command of the Sanskrit language.

There is another reason why a knowledge of Sanskrit is vital to the proper 
understanding and interpretation of ayurveda. Āyurvedic therapy is very largely a herbal medicine. Thousands of herbs are mentioned in the literature. While many of these are clearly identified, there remains an important body of medicinal herbs whose identity is not certain. Research using botanical, historical, and literary sources can often clarify these matters, but this research depends essentially on a knowledge of Sanskrit.

Therefore, the production of reliable information on ayurveda will be a task to be shared by Sanskritists, historians, and doctors.

Promoters of ayurvedic medicine normally make a strong appeal to the long history of this type of medicine. This is an integral feature of the appeal and popular validation of this therapy. However, the strength and ubiquity of these appeals is normally matched by a dismal absence of any substantial historical understanding. Training courses in ayurveda do not normally include modules on the history of the science, and the lack of general historical knowledge about Indian medicine amongst practitioners is shocking. Platitudes about ayurveda originating thousands of years $\mathrm{BC}$ are distressingly common. The many changes and developments in ayurveda which have taken place historically over the centuries are commonly elided in preference for an image of ayurveda as a timeless incarnation of medical truth. This lack of general historical knowledge is damaging because false information circulates in the public sphere, and this is likely to mislead potential patients. Because ayurvedic practitioners normally stress the importance of the long history of ayurveda as a principal virtue of the system, it is vital for correct information on the history of ayurveda to be prominently available.

I would therefore encourage the Committee to consider most seriously the question of the provision of reliable, historically-informed information about ayurveda. This subject is intimately linked to that of the education and regulation of ayurvedic practitioners.

\section{Research}

Double-blind placebo clinical trials are today necessary to create confidence amongst doctors and patients. But it is important to be aware that ayurvedic herbal medicine is normally delivered in compounds consisting of dozens, sometimes scores of individual substances. Clearly there is a need to conduct trials which use not just simples, but these complex herbal compounds. The interactions between the constituents in a compound may be crucial to its modus operandi. This may greatly complicate the testing of ayurvedic medicines.

I would also note that it is critical that research into ayurveda should also include the participation of sociologists, anthropologists, ethnopharmacologists, and scholars of ethnomedicine, bioethics, biodiversity, and ecology. These are all 


\footnotetext{
${ }^{14}$ FRLHT; http://ece.iisc.ernet.in/ernet-members/frlht.html.

${ }^{15}$ [The Wellcome Institute was closed in 2002 , and the research and teaching staff moved to the new Wellcome Trust Centre for the History of Medicine at University College London, where this BSc continues to be taught.]
} 
The Centre for Complementary Health Studies at University of Exeter is one of the few centres of higher education in Britain where postgraduate degrees in CAM can be taken. The Exeter CCHS has an excellent reputation (I have been an external examiner for their MPhil program), and hope that the Committee has an opportunity to benefit from the informed opinion of the teachers and managers of the Exeter program 16

The Government of India regulates the teaching and practice of ayurveda in India. There are hundreds of colleges nationwide which teach the Bachelor of Ayurvedic Medical Science (BAMS) and higher degrees. This system of collegebased ayurvedic education is mainly a post-independence development, modelled on Western medical education. Its establishment was highly controversial, and for good reasons. In pre-colonial times, education in ayurveda was principally conducted in traditional Sanskrit schools in which students started very young (10 or less), and were grounded for over 12 years in the Sanskrit language and in the medical literature. Apprenticeship to a practising physician was also essential. Unlike China, pre-modern Indian did not develop a system of medical licensing, and the right to practice, as well as professional success, were a function of good reputation, training by a famous teacher, and sometimes court patronage.

Many people, especially biomedically-trained practitioners in India, view ayurveda and biomedicine as being fundamentally different in their presuppositions, methods, and understandings of the human body and its functions. Critics of the college-based ayurvedic education, which aims to teach a mixture of ayurveda and basic medical science, argue that these colleges produce students who are neither fish nor fowl: they are not trained thoroughly in either ayurveda or biomedical science. Standards in Sanskrit language are very poor; teaching is in English or the local state language. The educational situation in India is complicated by the fact that a training in ayurvedic medicine is sometimes seen as an option for students who fail entry requirements for biomedical medical school but who still want a profession in medicine.

In my opinion there is no easy answer to the question of ayurvedic education for practitioners. Clearly a return to a pre-modern full-immersion/apprenticeship system is impossible, although some experiments in this direction at the ayurvedic college in Coimbatore have been strikingly successful. The problem of quality, both of students and of teaching, is critical.

If ayurveda is to form part of the health care portfolio in modern Britain, some planning and regulation of ayurvedic education will be essential. For the time being, the BAMS degree is probably a minimum qualification level below which practice in Britain should not be permitted. But the BAMS by itself may

\footnotetext{
${ }^{16}$ [Most regrettably, this centre was closed in mid-2004.]
} 
not be enough to provide adequate or appropriate training for a physician working in a modern environment in Britain.

\section{Regulation and Risk}

A criticism sometimes levelled at ayurveda is that its medicines contain dangerous heavy metals. I should like to note for the Committee that the classical foundational reference encyclopedias of ayurveda make almost no use of metals whatever. It is certainly valid to argue that a 'pure' form of ayurvedic therapy does not use metals or metallic compounds, but relies exclusively on herbal compounds, oils, and a selection of animal products. Metals came into medical use only at a relatively late time in India, broadly coinciding with the advent of Islam and the Moghul period. (There are unanswered historical questions here.)

Clearly the public must be protected from dangerous medication. This is valid for all forms of medicine, biomedical or CAM.

In his submission to the Committee, Ivan Corea, Fellow at the King's Fund, has recommended the establishment of a Complementary Medicine Commission with associated Regulatory Bodies. I am in full agreement with the his views on this matter.

\section{National Health Service Provision in the UK}

Britain today has a large minority population of people of South Asian ethnic background. Áyurvedic ideas and therapies are deeply embedded in Indian culture, and have an immediate appeal and meaning for even second and third generation Asians. This has obvious implications for both patients and doctors.

In the clinical encounter, a patient of Indian ethnic background presenting to a doctor may use unfamiliar language and symbolism to describe symptoms. For example, a simple statement such as 'I am hot' (or 'I have been eating heaty food') can have a humoral connotation for a person whose foods are traditionally classified into hot and cold categories which have nothing to do with temperature. It would be advantageous to NHS doctors to have at least a basic understanding of the medical concepts and presuppositions that are likely to be present in patients from these communities and with cultural backgrounds that include many ayurvedic traditions.

I also believe that a move to make ayurvedic treatments available through the NHS would meet an extremely positive response from the Indian ethnic communities in Britain.

The appeal of ayurveda to the wider population in Britain as part of CAM is certain to continue growing, and with it will grow the demand for its therapies through the NHS. 
Certain ayurvedic oil massage therapies do seem to be non-threatening, external, and of proven value in a range of rheumatic and related ailments. This would seem to be a reasonable and non-controversial starting point for experiments in offering selected ayurvedic therapies through the NHS. Standards for evaluating this type of therapy are comparable with those already in use for physiotherapy and osteopathy.

\section{The Government Response to the Report: 2001}

As mentioned above, the House of Lords Report produced strong reactions in the CAM community of practitioners and organisations, reactions which continue to reverberate. Less publicised was the fact that the Report was followed by a formal response published by the Department of Health (henceforth the 'Response') ${ }^{17}$

\section{Discussion}

The Response is interesting for several reasons. It traversed the original Report paragraph-by-paragraph, offering comments, qualifications and further information. The most common phrase at the start of each paragraph is 'The Government agrees...'. The Response was indeed in general agreement with the original Report in wishing to see an increase in regulation and control of the CAM profession, coupled of course with increased standardization of education and practice. And yet, the Response projected a rather different overall atmosphere. Where the Report may appear somewhat strident and overbearing, the Response appears more emollient and reasonable. For example, on the key issue of the Report's notorious 'three groups,' the Response did not reject the categorisation, but did accept that it is 'necessarily broad in nature, and it need not imply that all therapies in each category have identical features.' The Report continued,

In some circumstances there may also be scope for some therapies to be allied for a specific purpose across the boundaries of the proposed groupings. For example the Government considers that, for the purposes of professional self-regulation, those aspects of the traditional therapies listed in Group 3a which include the use of herbal remedies could come together within a federal grouping of therapies in Group 1 under the general heading of herbal medicine, while still retaining their individual identities and traditions. It may also be possible to bring within Group 1 those aspects of traditional therapies which practise

\footnotetext{
${ }^{12} \sqrt{\text { The Secretary of State for Health }} \mid 2001$.
} 
acupuncture. Under the general headings of herbal medicine and acupuncture, there would therefore be scope to protect the public by affording statutory recognition to large parts of these more traditional therapies... 18

This is a far more trenchant criticism of the Report's central classification than the mild language would suggest. The Government was in fact recognising the point made above (5) that the Report had separated some practitioners of identical practices, such as herbal medicine and acupuncture, into separate groups apparently as a result of effective lobbying by practitioners, or a rejection of underlying medical models, rather than on the basis of the actual medical methods involved.

The Response stated that the Department of Health had taken three practical steps. First, it had commissioned the Foundation for Integrated Medicine to conduct an assessment of existing reports on consumer preferences in CAM. Second, as part of its annual survey of NHS patients, the Department had also asked NHS cancer patients to identify their use of complementary therapies. Finally, the Department had commissioned the Office of National Statistics to include questions on the use of complementary medicine in its National Statistics Omnibus Survey in March 2001.

The Response mentions the Prince of Wales's Foundation for Integrated Health at several points, tacitly accepting this organisation as a key reference resource in developing information and policy for CAM regulation. This Foundation is an independent consultancy closely linked with the Prince Charles, the Prince of Wales. The current board of Trustees includes senior figures from the medical establishment, representative practitioners of osteopathy, homoeopathy, herbal medicine and establishment medicine, lawyers, educators and journalists. Its mission is to promote patient choice, especially in the area of CAM therapies, to encourage CAM professions to develop and maintain statutory or voluntary systems of self-regulation as well as nationally recognised standards of education and training, and to increase the capacity for research into CAM ${ }^{19}$ The Foundation is committed to promoting 'an holistic and integrated approach to healthcare which engages with all aspects of a patient's being including mind, body and spirit and which takes into consideration environmental, psychosocial and nutritional aspects of health', ${ }^{20}$

${ }^{18}$ The Secretary of State for Health 2001,4

${ }^{19}$ The Foundation's website is http://www.fihealth.org.uk/

${ }^{20}$ Cited from the Foundation's website, http://www.fihealth.org.uk/fs_what_we_do. html, October 2004. 


\footnotetext{
${ }^{21}$ The paragraphs referred to in these quotations are references to the original House of Lords Report.
}

'CAM can also play a part in treating NHS patients. But if it aspires to be an equal player with other forms of NHS treatment, it must meet the same standards required of them.' (Response, p. 1)

'We recommend that familiarisation should prepare medical students for dealing with patients who are either accessing CAM or have an interest in doing so. This familiarisation should cover the potential uses of CAM, the procedures involved, their potential benefits and their main weaknesses and dangers (para 6.77).' (Response, p. 12)

'We recommend that every medical school ensures that all their medical undergraduates are exposed to a level of CAM familiarisation that makes them aware of the choices their patients might make (para 6.79).' (Response, p. 12)

'... and CAM therapists should encourage patients with conditions that have not been previously discussed with a medical practitioner to see their GP' (Response, p. 17)

The subtext in such passages is that patients who make unorthodox choices of therapy must be protected from their own folly and from the predations of quacks. This is quite a different premise to that of the Foundation for Integrated Health, which is interested in,

Emphasising the key importance of individuals taking more responsibility for their own healthcare, which requires teamwork amongst patients and healthcare practitioners. (Foundation website, ibid.)

The Report and the Response were interesting on the topic of the socalled placebo effect. The Report put its opinion in the following terms:

In our opinion any therapy that makes specific claims for being able to treat specific conditions should have evidence of being 
able to do this above and beyond the placebo effect. This is especially true for therapies which aim to be available on the NHS and aim to operate as an alternative to conventional medicine, specifically therapies in Group 1. The therapies in our Groups 3a and b also aim to operate as an alternative to conventional medicine, and have sparse, or non-existent, evidence bases. Those therapies in our Group 2 which aim to operate as an adjunct to conventional medicine, and mainly make claims in the area of relaxation and stress management, are in lesser need of proof of treatment-specific effects but should control their claims according to the evidence available to them....22

And the Government responded,

The Government agrees with the need for strong evidence beyond the placebo effect to support the use of any complementary therapy in Groups 1 and 3 on the NHS. The test proposed - i.e. that any treatment that makes specific claims should have evidence of benefit above and beyond the placebo effect - is a tough one. However this is the right standard to set for therapies in Groups 1 and 3, especially as the report goes on to accept that therapies which are mainly about relaxation and stress management and make only limited claims, need not satisfy this particular test. ${ }^{23}$

These statement exemplify well some of the topics discussed by the medical anthropologist Moerman 2002. Moerman has developed the concept of the 'meaning-response' to replace the term 'placebo'. By doing this, Moerman refocusses the debate about medication and treatment to privilege the recovery of patients over the application of therapy. He provides much carefully evaluated statistical evidence that shows how patients become sick and well in response to the meanings of their experiences, which include actual chemical drug effects, but also a wide range of responses to the cultural, social and ultimately semiotic content of their experience. The fact is, patients get well for many reasons, only some of them connected with the drugs administered by doctors.

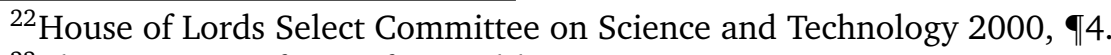

${ }^{23}$ The Secretary of State for Health 2001, 5-6. 


\section{Medical Error, Medical Truth}

And patients often become ill as a result of Modern Establishment Medicine (MEM) therapies. It is now almost thirty years since Illich delivered his famous thundering critique of MEM, with its ringing opening sentence:

The medical establishment has become a major threat to health. The disabling impact of professional control over medicine has reached the proportions of an epidemic. ${ }^{24}$

Illich claimed that at the time he wrote iatrogenic illnesses were causing between 60,000 to 140,000 deaths in America each year, and leaving 2 to 5 million others more or less seriously ill. Moreover, the situation was worst at the heart of the medical establishment, i.e, university hospitals where one in five patients contracted an iatrogenic disease which usually required special treatment and led to death in one case out of thirty. Iatrogenic disease has continued to be a major problem. The drug scandal surrounding Ciba-Geigy's Clioquinol, for example, reveals processes at work within MEM which run counter to the vision of MEM as a purely rational and science-based process. It took eight years from the clinical demonstration that Clioquinol caused subacute mylo-optic neuropathy for Ciba-Geigy to withdraw the drug. Even then, the company was not acting on the scientific evidence, but because of an international campaign against the drug by its victims and their doctors ${ }^{25}$ The editor of the British Medical Journal noted in 1995 that only 15\% of biomedical interventions are supported by solid scientific evidence. ${ }^{26}$ In August 2004, the British Medical Journal published an analysis of the first results to come from the recently-formed National Patient Safety Agency. ${ }^{27}$ This agency draws together reports of errors regarding the safety of patients and systems-failures that are provided by health professionals across England and Wales. The report found, incredibly, that, 'About 850,000 medical errors occur in NHS hospitals every year, resulting in 40,000 deaths.' And yet only 4000 misadventures are reported per annum, and only $2.2 \%$ of all hospital episodes contain any mention of an adverse event. The conclusion is stark: the medical profession is not being honest with itself or with the public about the nature and extent of lethal error in its own practice.

The processes at work within MEM are complex, and highly influenced by issues of finance, corporate culture and, above all, politics. In the

${ }^{24}$ Illich 1976, 1.

${ }^{25} \overline{\text { Shiva } 1988,251-53 .}$

${ }^{26}$ The Editor 1995. For further informed discussion see Horton 2003.

27 Aylin et al. 2004. 
present context, where a government is attempting to use one set of medical professionals to regulate another, we may recall another of Illich's trenchant passages:

... the insistence of the medical guild on its unique qualifications to cure medicine itself is based on an illusion. Professional power is the result of a political delegation of autonomous authority to the health occupations which was enacted during our century by other sectors of the university-trained bourgeoisie: it cannot now be revoked by those who conceded it; it can only be de-legitimized by popular agreement about the malignancy of this power ${ }^{28}$

The work of Britain's National Patient Safety Agency shows that there is an incontestible case for practitioners of MEM to put their own house in order, to admit and integrate the now-public fact that one in ten people entering hospital will experience a medical error, and that half of these errors are preventable. It is only once the dangers and failures of MEM are honestly faced that improvement in safety can begin.

All this does not, of course, automatically mean that CAM practice is good. But it does mean that naive arguments against the safety and effectiveness of CAM based on an assumed contrast with MEM can no longer be taken seriously.

Arguments concerning the pervasiveness of iatrogenic disease in MEM and the primacy of guild politics in the control of public medicine have been with us for a long time. If these are are given due consideration, then medical authorities and practitioners might be expected to show greater interest in evaluating a wider range of safe therapies, including meaningresponses (placebos). The meaning-response, or placebo, demonstrably produces wellness in many patients, both in MEM as well as in CAM. If the aim of medicine is to cure patients, then it is hard to see why the meaningresponse is cast as the epitome of poor medicine in the documents under discussion. This is a large and subtle subject, raising many difficulties, and it cannot be explored here. But it has to be said that the Government Response, like the Report before it, is strikingly unsophisticated concerning matters that have been the staple of medical anthropologists and medical

${ }^{28}$ Illich 1976, 14. 
sociologists since the 1960s, not only matters concerning the placebo effect, but meta-issues concerning the whole process of medical professionalisation and modernization. ${ }^{29}$ Modern work towards a anthropologicallyinformed view of healing processes in the context of contemporary medicine may be traced back at least as far as the work of Rivers during the First World War, ${ }^{30}$ just one example of excellent work in this area that is relevant to the Asian medical traditions is that of Bannerman and his colleagues, ${ }^{31}$ but of course it is the medical anthropologist Charles Leslie who has perhaps done most to develop a modern understanding of Asian medicine as it enters and interacts with the modern world ${ }^{32}$ The absence of any reference to the considerable body of work achieved in the last fifty year by medical anthropology and related fields lends a curious and unexpectedly archaic feeling to the present Government documents, which share several features of style and unreflective hegemonic discourse with some early twentieth-century reports on medical regulation in India. ${ }^{33}$

Neither the Report nor the Response make any reference to the considerable body of work on Traditional Medicine published in recent years by the World Health Organisation. This is a striking omission. The WHO has a department devoted to Traditional Medicine, and has in recent years developed an active program for the appropriate describing, evaluating and promoting the traditional medical systems of many countries. ${ }^{34}$ It has also published important documentation on them, including meta-studies on appropriate methods for evaluating herbal therapeutics. ${ }^{35}$ Its publication WHO Traditional Medicine Strategy 2002-2005, 36 for example, presents the core of the WHO Strategy for Traditional Medicine for 2002-2005. It provides brief information on the growing needs and challenges faced by traditional medicine worldwide. It also gives key messages and a checklist for the safety, efficacy and quality to policy-makers. Finally, it sets out WHO's role and how the WHO Strategy could meet the challenges to support WHO Member States in the proper use of traditional and complementary/alternative medicine. The Government's Response showed some evidence of a wider awareness of work in this field when it made reference

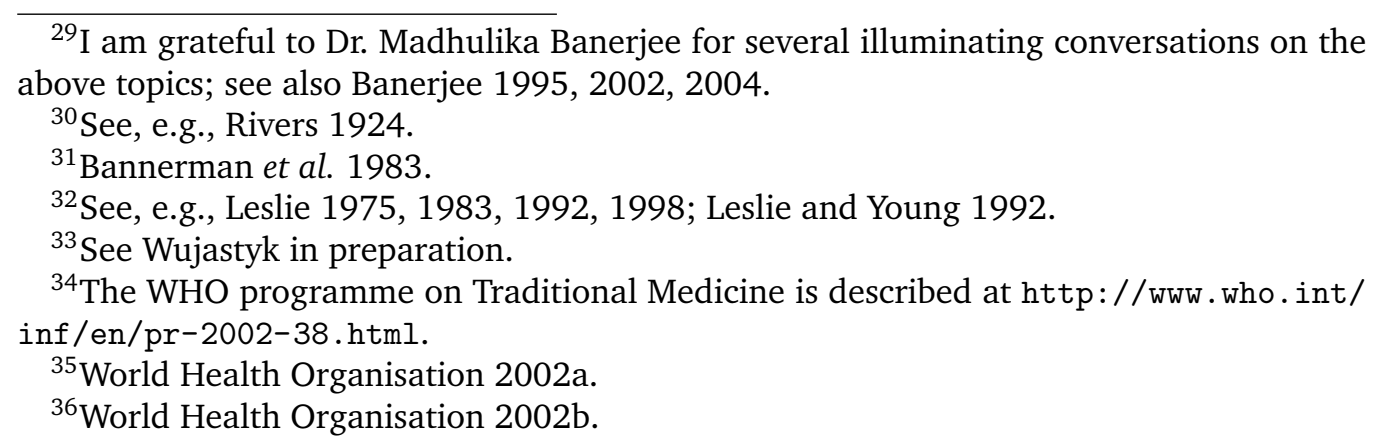


to a preliminary draft of a directive on traditional medicinal products circulated to member states of the European Commission. ${ }^{37}$ Nevertheless, the omission of any reference to WHO documentation or policy is a matter for serious concern when coming to a judgement about the trustworthiness of the UK government's Report and Response or the breadth of consultation that went into them.

\section{Proposals for Statutory Self-Regulation: 2003}

The most recent Governmental development at the time of writing is the Department of Health's publication of a document entitled Regulation of Herbal Medicine and Acupuncture. Proposals for Statutory Regulation (henceforth Proposals) ${ }^{38}$ This document locates itself as a direct successor of the Report and the Response (p.5). It is based on the reports of two working groups established in 2002. The first was the Herbal Medicine Regulatory Working Group (HMRWG), consisting of representatives from the Department of Health, the Prince of Wales's Foundation for Integrated Health and the European Herbal Practitioners Association. The second was the The Acupuncture Regulatory Working Group, which was jointly established by the Department of Health and the Prince of Wales's Foundation for Integrated Health 39

The Proposals conclude that a statutory regulatory system is considered necessary in order to ensure patient and public protection. A period of further public consultation, to end in June 2004, will lead to an amended partial regulatory impact assessment, which will reflect the outcome of the consultation process, and this will also be subject to further consultation. The final goal is to prepare a draft Order under section 60 of the Health Act 1999 in order to establish the new statutory system.

Initial public reaction to this new Proposal has been nervous. It has been argued on the basis of the previous introduction of statutory self-regulation in medical practices such as osteopathy, that participation in the regulatory system is likely be prohibitively expensive for even highly qualified and successful practitioners. ${ }^{40}$

It appears that the British Government's movement towards the establishment of statutory self-regulation bodies for the governance of the various types of CAM has achieved a momentum that will not be deflected. It

\footnotetext{
37 The Secretary of State for Health 2001, 9.

${ }^{38}$ Department of Health 2004.

${ }^{39}$ The reports of these two working groups, published in 2003, are separately available as http://www.advisorybodies.doh.gov.uk/herbalmedicinerwg/ and http:// Www .advisorybodies.doh.gov.uk/acupuncturerwg/.

${ }^{40} \mathrm{~S}$ See, for example, the report in The Economist (Anonymous 2004, 30).
} 
is regrettable that the preparation of the various policy documents which define the present situation did not make use of the full spectrum of knowledge and information that could have thrown more light their deliberations. It is also regrettable that such a bluntly hegemonic approach to CAM has been the informing principle behind these documents, in stark contrast, for example, to the approaches taken by the WHO. The regulating bodies that result from the present initiatives will have to struggle with the legacy of these shortcoming. 


\section{References}

Anonymous, 2004, 'Quacks Unite: Getting Organised, and Turning Respectable', The Economist, 370, 8365: 30.

Aylin, Paul, Shivani Tanna, Alex Bottle and Brian Jarman, 2004, 'Dr Foster's case notes: How often are adverse events reported in English hospital statistics?', British Medical Journal, 329: 369.

Banerjee, Madhulika, 1995, Power, Culture, Medicine: A Study of Ayurvedic Pharmaceuticals in India, Ph.D. thesis, University of Delhi, Department of Political Science, Delhi.

Banerjee, Madhulika, 2002, 'Public Policy and Ayurveda; Modernising a Great Tradition', Economic and Political Weekly, XXXVII, 12: 1137-46.

Banerjee, Madhulika, 2004, 'Local Knowledge for World Market: Globalising Ayurveda', Economic and Political Weekly, XXXIX, 1: 89-93.

Bannerman, Robert H., John Burton and Ch'en Wen-Chieh, 1983, Traditional Medicine and Health Care Coverage: a Reader for Health Administrators and Practitioners, Geneva: WHO.

Department of Health, 2004, Regulation of Herbal Medicine and Acupuncture. Proposals for Statutory Regulation, Department of Health Document no. 34352, Leeds: Department of Health, URL http://www.dh.gov.uk/ Consultations/LiveConsultations/fs/en.

Horton, Richard, 2003, Second Opinion. Doctors, Diseases and Decisions in Modern Medicine, London: Granta Books.

House of Lords Select Committee on Science and Technology, 2000, 'Complementary and Alternative Medicine', Government Report 6 of 1999-2000, House of Lords, House of Lords, Westminster, URL http: //www . parliament . the-stationery-office.co.uk/pa/ ld199900/ldselect/ldsctech/123/12301.htm.

Illich, Ivan, 1976, Limits to Medicine: Medical Nemesis: The Expropriation of Health, London: Penguin, Illich (1986) gives a ten-year retrospective on Medical Nemesis.

Illich, Ivan, 1986, 'Body History', The Lancet, 1325-27.

Kleinman, Arthur, Peter Kunstadter, E. Russell Alexander and James L. Gale (eds.) 1975, Medicine in Chinese Cultures: Comparative Studies of Health Care in Chinese and Other Societies. Papers and Discussions from a Conference held in Seattle, Washington, U.S.A., February 1974, Washington D.C.: John E. Fogarty International Center for Advanced Study in the Health Sciences.

Leslie, Charles, 1975, 'Pluralism and Integration in the Indian and Chinese 
Medical systems', in Kleinman et al. (1975), chapter 24, 401-17, commented on in Obeyesekere (1975).

Leslie, Charles, 1983, 'Legal Aspects: Policy Options Regulating the Practice of Traditional Medicine', in Bannerman et al. (1983), 314-317.

Leslie, Charles, 1992, 'Interpretations of Illness: Syncretism in Modern Āyurveda', in Leslie and Young (1992), 177-208, repr. Munshiram Manoharlal, Delhi.

Leslie, Charles, 1998, 'The Ambiguities of Medical Revivalism in Modern India', in Leslie, Charles (ed.) Asian Medical Systems, Indian Medical Tradition, vol. 3, 356-67, Delhi: Motilal Banarsidass, 2nd edition, first published Berkeley, London: U. California Press, 1976.

Leslie, Charles and Allan Young (eds.) 1992, Paths to Asian Medical Knowledge: a Comparative Study, Berkeley, Oxford, etc.: University of California Press, repr. Munshiram Manoharlal, Delhi.

Moerman, Daniel, 2002, Meaning, Medicine and the 'Placebo Effect', volume 9 of Cambridge Studies in Medical Anthropology, Cambridge: Cambridge University Press.

Obeyesekere, Gananath, 1975, 'Some Comments on the Nature of Traditional Medical Systems', in Kleinman et al. (1975), chapter 25, 419-25.

Ramsey, Matthew, 1999, 'Alternative Medicine in Modern France', Medical History, 43, 3: 286-322.

Rivers, W. H. R., 1924, Medicine, magic, and religion : the Fitz Patrick Lectures delivered before the Royal College of Physicians of London in 1915 and 1916, London: K. Paul, Trench, Trubner \& Co., ltd.

Shankar, Darshan, 1995, 'Epistemology of Traditional Medicinal Knowledge System of India', in Pushpangadan, P., Ulf Nyman and V. George (eds.) Glimpses of Indian Ethnopharmacology, chapter 3, 19-28, Thiruvananthapuram and Copenhagen: Tropical Botanic Garden and Reseach Institute and The Royal Danish School of Pharmacy.

Shankar, Darshan and Ram Manohar, 1995, 'Ayurveda Today: Ayurveda at the Crossroads', in van Alphen and Aris (1995), 99-105.

Shiva, Vandana, 1988, 'Reductionist Science as Epistemological Violence', in Nandy, Ashis (ed.) Science, Hegemony and Violence: a Requiem for Modernity, chapter 7, 232-256, New Delhi: Oxford University Press, 6th edition.

The Editor, 1995, 'Editorial', British Medical Journal, 303, 6806: 155-6.

The Secretary of State for Health, 2001, 'Government Response to the House of Lords Select Committee on Science and Technology's Report on Complementary and Alternative Medicine', Government Report 
Cm 5124, Government of Britain, London, URL http://www.archive. official-documents.co.uk/document/cm51/5124/5124.pdf.

van Alphen, Jan and Anthony Aris (eds.) 1995, Oriental Medicine: an Illustrated Guide to the Asian Arts of Healing, London: Serindia Publications.

World Health Organisation, 2002a, Traditional Medicine - Growing Needs and Potential, volume 2 of WHO Policy Perspectives on Medicines, Geneva: World Health Organisation, URL http://www.who.int/ medicines/library/trm/trm_polpers_eng.pdf.

World Health Organisation, 2002b, WHO Traditional Medicine Strategy 2002-2005, Geneva: World Health Organisation, URL http://www . who. int/medicines/library/trm/trm_strat_eng.pdf.

Wujastyk, Dominik, 1993, 'Indian Medicine', in Bynum, W. F. and Roy Porter (eds.) Companion Encyclopedia of the History of Medicine, volume 1, chapter 33, 755-778, London: Routledge, 2v.

Wujastyk, Dominik, 1995, 'Medicine in India', in van Alphen and Aris (1995), chapter $1,18-37$.

Wujastyk, Dominik, 1998, The Roots of Āyurveda: Selections from Sanskrit Medical Writings, New Delhi: Penguin.

Wujastyk, Dominik, 1999, 'Miscarriages of Justice: Demonic Vengeance in Classical Indian Medicine', in Hinnells, John and Roy Porter (eds.) Religion, Health, and Suffering, 256-75, London: Kegan Paul International.

Wujastyk, Dominik, in preparation, 'The Evolution of Government Policy on Ayurveda in the Twentieth Century', in Benner, Dagmar and Fred Smith (eds.) Pluralism and Paradigms in Modern and Global Ayurveda, New York: SUNY Press. 